\title{
Introduction
}

Whether we notice or not, our days are filled with listening. Of course, you will object: some people more than others, some countries more than others, some economies more than others, and this is true. But a colleague told me he heard music in a supermarket on a dirt road in South Africa, so let us not leap to conclusions about the lives of others. ${ }^{1}$ Nonetheless, I will be happy here to think about England and the United States, the two countries where I've lived, and to a lesser extent, Canada and western Europe, where I have frequently traveled and have discussed these issues with colleagues and students.

Ubiquitous Listening is about the listening that fills our days, rather than any of the listenings we routinely presume in musicology, sociology, media studies, and elsewhere. The problem I am addressing is not a disciplinary one-it crosses fields and disciplines blithely. How do we listen to the music we hear everywhere, and how does that listening engage us and activate the world we move in?

My basic thesis is this, put bluntly: Ubiquitous musics, these musics that fill our days, are listened to without the kind of primary attention assumed by most scholarship to date. That listening, and more generally input of the senses, however, still produces affective responses, bodily events that ultimately lead in part to what we call emotion. And it is through this listening and these responses that a nonindividual, not simply human, distributed subjectivity takes place across a network of music media.

Since these six terms-ubiquitous musics, affect, the senses, attention, listening, and distributed subjectivity - are at the core of everything that follows, they bear some defining. 


\section{UBIQUITOUS MUSICS}

What we listen to most is what I have termed "ubiquitous musics." I took the term ubiquitous from Mark Weiser's idea of ubiquitous computing, in which computing power would be embedded in everyday objects, including walls, clothing, and the like (Weiser 1991; see also chapter 1). Similarly, ubiquitous musics come out of the wall, our televisions, our video games, our computers, and even out of our clothing (see, for some examples, the range of clothing with pockets for $\mathrm{MP}_{3}$ players and sleeves for earphone cords, or Oakley-Thump, the world's first digital music eyewear, or temperature-regulating ski jackets). ${ }^{2}$ Workplaces, shops, homes, cars, buses, trains, phones, restaurants, clubs . . . music is everywhere, some through our own choices, some without our sanction or control. Of course, ubiquitous music preceded Weiser's article by some sixty years-it is the first ubiquitous mediated experience after print. The point is not that ubiquitous computing is a metaphor for ubiquitous music, but rather that an idea (of embedding things in everyday life) that we think of as coming from computing long preceded it - though the significance of radio, Muzak, and phonographs was perhaps not obvious at first.

In his delightful book Elevator Music (2004), Joseph Lanza has argued that ubiquitous musics (though he doesn't use the term, of course) are a quintessentially twentieth-century technology. Like thermostats, he says, they allow us to control our environments (70). It is certainly true that the technologies of ubiquitous music — radio and Muzak and the phonograph, then hi-fis, transistor radios, tape decks, Walkmen, CD players, Internet radio, satellite radio, $\mathrm{MP}_{3}$ players, and so on-are produced and taken up steadily throughout the twentieth century. Moreover, at the turn of the nineteenth to the twentieth century, there was virtually no music without musicians present in the same room, whereas by the end of the century, music was everywhere, from the office to the shower, and many of us couldn't imagine life without it. My daughter, who is currently twentytwo, would prefer to have music on in the background always, or at least almost always, and most of my students seem to be roughly the same, according to what they say about their own listening habits. They say they're most often not paying attention to the music; they just want it as a background accompaniment to their routines and activities.

\section{AFFECT}

But what are all these ubiquitous musics doing, as we listen to them in so many different places and ways? Are they hailing us, in a process of 
Althusserian subject formation? Are they purveyors of ideologies? Do they constitute us as subjects? While works that argue such things-most notably Susan McClary's Feminine Endings-came to the fore in the early 1990 in the field of musicology, analyzing the Western art music canon of modernity, such analysis didn't spread more widely into ethnomusicology and popular music studies, though critical musicology is still, from some perspectives, a growing tradition. But if pieces of music aren't hailing us as bourgeois subjects, what are they doing? Especially at these lower levels of attention? It seems clear that they are operating in a different modality altogether, and I am proposing that that modality is affect. Affect is the circuit of bodily responses to stimuli that take place before conscious apprehension. Once apprehended, the responses pass into thoughts and feelings, though they always leave behind a residue. ${ }^{3}$ This residue accretes in our bodies, becoming the stuff of future affective responses.

To take a simple example, then, my eyes used to well up with tears at a particular phone company ad on television. When I could register my thoughts and feelings - that the ad was stupid and calculating, commodifying the feelings of people with distant family and lovers just to sell phone service-I was wholly repulsed by the ad. But it worked on me before that analysis slipped into place, which was very quickly. Nonetheless, my affective response was even faster, and the tears came before the dislike of the ad.

\section{SENSES}

Scholarship on affect is also closely connected to a renewed interest across the disciplines in the senses. There are many examples of such works, and the fascinating, wonderful outpouring of books on sound over the last couple of years is one subset among them-we are suddenly paying attention to sound with a new vigor. For just some examples of exciting work in sound studies, Jonathan Sterne's The Audible Past: Cultural Origins of Sound Reproduction (2003) treats the history of sound reproduction to consider our very notions of sound. Fred Moten's brilliant In the Break: The Aesthetics of the Black Radical Tradition (2003) takes improvisation, heard (not only) through sound and music, as the very structure of blackness, and uses what he helps us to hear as a specifically and strenuously black critique of Western philosophy to bring a black radical tradition into focus. Richard Cullen Rath's How Early America Sounded (2005) compares the soundways of European, First Nations, and Africans in early 
America. John Picker's Victorian Soundscapes (2003) considers how sound is represented in the period by novelists, philosophers, and scientists. Emily Thompson's The Soundscape of Modernity (2002) discusses architecture and sound design and what they tell us about modernity. Hearing Cultures (2004), edited by Veit Erlmann, compellingly suggests that considerations of sound will irrevocably change our thinking about times, places, and cultures. His latest book, Reason and Resonance: A History of Modern Aurality (2010), is an intellectual history of listening, or perhaps more to the point thinking about listening, in western Europe. Mark Smith's Listening to Nineteenth-Century America (2001) contends that even the most fundamental identities in the period-northern versus southern, slave versus free-were constructed in sound, while Karin Bijsterveld's Mechanical Sound: Technology, Culture, and the Public Problems of Mechanical Noise in the Twentieth Century (2008) considers noise and its regulation in Europe and North America. And these, and many others, are all within the last ten years.

And this doesn't even include music therapy or the literature on listening in counseling and education. Relatedly, there is a growing body of work on film sound, including The Sounds of Early Cinema (2001), edited by Richard Abel and Rick Altman; James Lastra's Sound Technology and the American Cinema: Perception, Representation, Modernity (2000); Jay Beck and Tony Grajeda's Lowering the Boom (2008); Steve Wurtzel's Electric Sounds: Technological Change and the Rise of Corporate Mass Media (2007); and the journal Music, Sound, and the Moving Image. ${ }^{4}$

Throughout this book, I am connecting listening, sound, attention, and affect as a way to theorize the relationship between ubiquitous musics and distributed subjectivities, and one way to get at those relationships is to begin from specific physical memories of specific musical events.

\section{AFFECT AND THE SENSES}

In June 2006 I went to a memorial concert for an old family friend, renowned oud player George Mgrdichian. It was held in a relatively small club in Greenwich Village in New York, and it was packed. Musicians such as the Waverly Consort, the Gerard Edery Ensemble, and David Amram played, and it was extraordinary. What it was emphatically not was a rock concert or a club night, so it was neither especially loud nor especially bass-y in the sound mix. 
Nonetheless, at several points the music flowed through the furniture into my thighs, back, and arms. This very immediate and contact experience in an unexpected context made me aware immediately of the many settings in which that experience is commonplace-for example, concerts, clubs, cars. ${ }^{5}$

The BBC did a segment in spring 2006 on what they represented as a new genre called dubstep. In it, Kode 9, a dubstep producer, says, "The thing that's consistent in the music is the sub-bass. You know, it's not too much mid-range bass frequencies that you get in drum and bass just now; it's got a solid sub-bass foundation, and as I said in an ideal world anything goes on top of that" (BBC 2006). His invocation of sub-bass made me think of many settings in which music (quite often what I would call ubiquitous music) is experienced through more than ears-not only those club nights where those in the know wear earplugs to protect their hearing while reveling in the music traveling through their feet and bodies, but also in cars, and in the homes of audiophiles, whose subwoofers on their high end Home Theater 5.1 surround-sound systems allow them to have similar body-vibrating aural experiences at will.

Dubstep DJ Joe Nice goes further: "It's a sound you can't really describe until you hear it, and it's not like you hear it in an iPod, you hear it in a CD player and you say 'OK, this sound is cool.' There's a physicality to the music, you know it's a physical listening experience. When you hear it on a big system, you hear it loud, you feel the bass move through your chest, you hear your ears get a little warm" (BBC 2006).

Feeling "the bass move through your chest" and hearing "your ears get a little warm" recasts any remaining notions of hearing as a distance sense, shifting it instead into coextension with touch. Certainly this idea evokes the image of Beethoven with his ear to the piano. In It's All Gone Pete Tong, made in 2004 by writer/director Michael Dowse, star deejay Frankie Wilde loses his hearing from the damage done in clubs pounding out dance music. He spirals downward into a continuous paranoid drug haze until he realizes one day that he can "hear" by placing his feet on the speakers and feeling the beat. Like profoundly deaf percussionist Evelyn Glennie, he conducts his career by feeling vibrations, primarily through his feet. As Glennie (1993) has said:

Hearing is basically a specialized form of touch. Sound is simply vibrating air which the ear picks up and converts to electrical signals, which are then interpreted by the brain. The sense of hearing is not the only sense that can do this, touch can do this too. If you are standing by the road and a large truck goes by, do you hear or feel 
the vibration? The answer is both. With very low frequency vibration the ear starts becoming inefficient and the rest of the body's sense of touch starts to take over. For some reason we tend to make a distinction between hearing a sound and feeling a vibration, in reality they are the same thing. Deafness does not mean that you can't hear, only that there is something wrong with the ears. Even someone who is totally deaf can still hear/feel sounds.

Thinking about the senses in this way, as a not rigidly differentiated field, is an idea that is very much coming into its own.

\section{TOUCH AND HAPTICS}

There has been a great deal of writing on touch recently, and particularly, in the wake of Deleuze and Guattari's A Thousand Plateaus (1987), on haptic media. Haptic is often taken to mean touch, and one finds the term frequently, for example, in discussions of computer interfaces. A search for haptic music turns up reams of articles on computer instrument interfaces, and again a large number on performers and performance. In contemporary media studies, however, haptic is not taken quite so literally. This sense of haptic comes, as I just mentioned, from Deleuze and Guattari, and it features prominently in works by theorists such as Laura Marks (2002) and Brian Massumi (2002). They take from A Thousand Plateaus the concept of Smooth and Striated space: "It seems to us that the Smooth is both the object of a close vision par excellence and the element of a haptic space (which may be as much visual or auditory as tactile). The Striated, on the contrary, relates to a more distant vision, and a more optical space-although the eye in turn is not the only organ to have this capacity" (Deleuze and Guattari 1987: 493; quoted in Marks 2002: xii). The intimacy of the senses with their theoretical world is here exceedingly clear: Striated space is allied with, though not limited to, an optical mode of apprehension, while Smooth space is haptic, that is, intimate, in contact, close, if not strictly speaking tactile.

It is this distinction that underwrites Laura Marks's wonderful book Touch (2002). She wants to offer a corrective to the often bleak, masculist, Eurocentric terrain of film theory, which has not succeeded in moving beyond an Enlightenment obsession with vision and perspective. Marks suggests that works in video and new media, in particular works by artists not from Euro-American cultures, often are haptic:

Haptic perception is usually defined as the combination of tactile, kinesthetic, and proprioceptive functions, the way we experience touch 
both on the surface of and inside our bodies. In haptic visuality, the eyes themselves function like organs of touch. Haptic visuality, a term contrasted to optical visuality, draws from other forms of sense experience, primarily touch and kinesthetics. Because haptic visuality draws on other senses, the viewer's body is more obviously involved in the process of seeing than is the case with optical visuality. The difference between haptic and optical visuality is a matter of degree, however. In most processes of seeing both are involved, in a dialectical movement from far to near, from solely optical to multisensory. And obviously we need both kinds of visuality: it is hard to look closely at a lover's skin with optical vision; it is hard to drive a car with haptic vision. (Marks 2002: 2-3)

Haptics then, are closely tied to erotics, to the dissolution of boundaries, to an erosion of self-other distinctions. For both Marks and Massumi, this is a shift from positioning and identification toward a more dynamic account of the relationship between us and the things with which we interact. As Massumi (2002) puts it, "The problem is no longer to explain how there can be change given positioning. The problem is to explain the wonder that there can be stasis given the primacy of process" $(7-8)$. This focus on process over position poses a challenge to theoretical models based on narrative and identification, though both are themselves processes.

\section{ANTIPOSITION}

Let us follow Deleuze and Guattari's "line of flight," in their language, away from narrative, alongside Marks and Massumi. The shift away from narrative identification and position draws a renewed focus onto somatic, haptic engagements with music (and other arts). As Marks (2002: 3) puts it: "Haptic images do not invite identification with a figure so much as they encourage a bodily relationship between the viewer and the image. Thus it is less appropriate to speak of the object of a haptic look than to speak of a dynamic subjectivity between looker and image."

Such a dynamic subjectivity demands a whole-cloth rethinking of the study of music. Following Deleuze and Guattari, and Marks after them, we can speak of auditory and haptic hearing; remember, they said that "the element of a haptic space ... may be as much visual or auditory as tactile" (Deleuze and Guattari 1987). ${ }^{6}$ If we take seriously the notion of a dynamic subjectivity, we will have to find a way to stop analyzing music as an object external to us, but rather to describe the dynamic nonhuman subjectivity that was in process in that small club in Greenwich Village. 
A dynamic subjectivity that comprises what we have for so long thought of as subject and object—scholar and music — might offer a way into thinking about ubiquitous musics. In fact, I want to go a step further than Marks: rather than a dynamic subjectivity between musicologist and music, or between subject (scholar) and object of study (e.g., a feature film), I am arguing that the two already share a large field of subjectivity, neither undifferentiated nor individualized, neither simply individual nor reductively social. Instead, I will argue that distributed subjectivity is a way of closing the gaps that plague us_-gaps between ourselves and our objects, between ourselves and our students, between ourselves and a whole range of others. But, perhaps surprisingly, even works like Touch and Massumi's Parables for the Virtual presume that the engagements between and among listener(s) and work(s) will be fully attentive, and yet many, perhaps even most, of those engagements are not fully attentive at all.

\section{ATTENTION}

Attention is another term that requires careful thought and explanation-and connects with a startling range of issues. There is a significant scholarly literature on attention in cognitive psychology and neuroscience, and more recently in economics. Beginning with Herbert Simon's key talk, "Designing Organizations for an Information-Rich World" (1971), attention is seen as a resource or commodity that is increasingly scarce. As Simon so presciently argues, in an information-rich world, the thing that information uses will become scarce. And that thing is attention. This is no small matter in the current context, when information, including creative product, is overwhelmingly produced at rates no one can consume. (This is especially a problem for media makers working in forms based on advertising revenue, who need to capture attention as their main commodity, and for advertisers, who believe that positive attention will translate into sales of their product. For an interesting take on the place of music in the problem of what is being called "the attention economy," see the literature on sonic branding, especially work by Steve Goodman [2010], Devon Powers [2010], Leslie Meier [2011], Joy Roles [2010]).

While serious focus in the study of culture on the question of attention is still fairly new, I would argue that attention of a particular kind is what the defenders of a structural classical listening intend and assume, and sometimes even state outright. As one brief example, consider Daniel Barenboim's Reith Lectures, including specifically this passage from the 
second one on 14 April 2006: "In other words what they are saying to the public is you don't have to concentrate, you don't have to listen, you don't have to know anything about it, just come and you will find some association, and we will show you so many things that have nothing to do with the music and this way you will go into the music. And I ask you, ladies and gentlemen, is that the answer to the so-called crisis in classical music?" But declarations such as these negate in one fell swoop most of the listening that most of us engage in every day-in the car, doing chores, on hold on phones, watching television, going to sleep, in the dentist's office.

While both Jonathan Crary (Suspensions of Perception: Attention, Spectacle, and Modern Culture, 1999) and Jonathan Beller (The Cinematic Mode of Production: Attention Economy and the Society of the Spectacle, 2006) have written admirable works on the question of attention, they are just scratching the surface of a truly huge question that we will have to confront in the arts and humanities, especially as attention becomes more and more fragmented with increasing numbers of new media forms. One important contribution to this problem is Katherine Hayles's (2007) essay, "Hyper and Deep Attention: The Generational Divide in Cognitive Modes," in which she argues that the deep, focused, long attention traditionally associated with the humanities is being replaced with a fragmented and multiple form of attention. Her focus is on the pedagogical implications of such a shift, but this is an important foray into the kinds of work on attention that are needed.

The questions of attention, and of reception or engagement more generally, will continue to press harder and harder on our theories as cultural forms become more and more interactive, and they are increasingly appearing in social theory concerned with immaterial labor, in economic studies trying to grapple with new forms of address to the senses, and in studies of affect. For the purposes of this study attention remains a central question: ubiquitous musics act, even when not engaged in a focused manner; the degree of attention one pays to them seems to rely on an enormous range of musicological, psychological, and sociological factors; and the relationship between listening and attention is anything but clear.

One way to think about this might be a kind of thought experiment: What would happen to (insert any piece of music here) if we considered the possibility that the piece was listened to in a restaurant while eating dinner with friends? or in my house while I'm cleaning? For example, in his chapter in Listening Subjects (1997) on the song "Intruder," David Schwarz describes Peter Gabriel's version this way: "Peter Gabriel's voice as he sings the verse is very close to the microphone; he sings purely, 
quietly, as if right into the ear of the listener. For me, it sounds as if Gabriel were putting his arm around the male listener's shoulders and sharing with him the narrator's fantasy of intruding into the space of a woman" (91).

What interests me here is the "arm around the shoulder" simile (and not the fact that the listener is presumed to be male, although that, too, is worthy of further thought). That fantasy structure, of Gabriel whispering into the listener's ear, seems to me to work in some settings every bit as Schwarz describes it, but it depends on a certain set of acoustic qualities, and this is the source of my question.

In order to hear Gabriel's chummy stalker whisper as the kind of intimacy Schwarz posits, it has to be in the audio foreground so that it can rise to the attentional foreground. When someone whispers in your ear, it fills your field of audition, after all. And all the literature on microphones and intimacy, on Bing Crosby and Frank Sinatra and Jean Sablon, depend on the listener's field of audition being filled by the sound (Frith 2008; McCracken 2001). But the majority of music we hear, we hear as auditory background, even if the industry insists on calling it foreground music.

So what happens to Schwarz's analysis of "Intruder" if it's listened to on tiny, tinny mono speakers with no bass at a low volume in a store while shopping for a new date outfit? There is, of course, no simple answer to this question, but I am clear that the fantasy Schwarz found does not work the same way in those circumstances as it does in the ones (he didn't quite notice that) he was imagining.

Of course, this problem-of attention and consciousness-is central to the study of film music, even if all that the best scholars have been able to say is that we're not supposed to notice classical Hollywood scores. This is how I first became interested in attention, during the writing of my PhD dissertation on film music (which eventually became Hearing Film, 2001). In the case of traditional approaches to Hollywood scoring, film music should be beneath both attention and consciousness. But that doesn't make the two the same thing.

In 1988, I went to Sweden to study with Philip Tagg, and while there I read parts of Ola Stockfelt's PhD thesis, Musik som lyssnandets konst ("Music as the Art of Listening"), a chapter of which appeared as "Adequate Modes of Listening" in Stanford Humanities Review, reprinted in Keeping Score. In it, he says:

For it to be possible to analyze this music adequately as it appears in everyday listening situations, a fragmented listening must guide us in determining both which parameters in the sounding music merit 
closer consideration in a more concentrated and reflexive study and how these parameters must be considered. Hence we must develop our competence reflexively to control the use of, and the shifts between, different modes of listening to different types of sounding events. In the same way that we must listen to the urban soundscape as "music" in order to make it more human, thereby developing the competence to draw up active goals for the "composition" of a more human sound environment, we must develop the competence to listen to that music precisely as a part of the soundscape in order to explain and change the position of music in this soundscape. Insofar as we strive to understand today's everyday music and/or want to develop pedagogical programs with real relevance for those who will live and participate in this musical life, we must develop our own reflexive consciousness and competence as active "idle listeners." (Stockfelt 1997: 143)

Such a posture toward music is counterintuitive, perhaps impossible. How can one study something to which one does not pay attention? How can one understand how people engage music inattentively through scholarly attention? And while reception can presumably be inattentive but conscious, can it be attentive but unconscious (in the sense of Freud's first topography) ? $?^{7}$ Or if so, which I think is correct, can it be fully not conscious? This last seems impossible, just as much as full, complete, rapturous attention does, but it bears further consideration. At the very least, however, it seems clear at this point that we need a notion of attention that includes a wide spectrum of activities that range between two impossible extremes-fully attentive and fully inattentive-and between modalities of the kind Hayles describes and more.

\section{LISTENING}

Of course, what is being done with varying degrees of attention is listening. I will say more about this in chapters 1 and 5 in particular, but for now at least a few words are in order. By listening, I mean a range of engagements between and across human bodies and music technologies, whether those technologies be voices, instruments, sound systems, or iPods and other listening devices. This wipes out, immediately, the routine distinction between listening and hearing that one often finds, in which the presumption is that hearing is physiological and listening is conscious and attentive. I insist, instead, that all listening is importantly physiological, and that many kinds of listening take place over a wide range of degrees 
or kinds of consciousness and attention. So, the term listening here pushes against most of its routine uses in scholarship.

Ideas about listening undergird most music scholarship, and most of them rely in one way or another on theories of narrative. In Introduction to the Sociology of Music (1988), for example, Theodor Adorno's typology of listeners valorizes the expert listener above all others: "The expert himself, as the first type, would have to be defined by entirely adequate hearing. He would be the fully conscious listener who tends to miss nothing and, at the same time, at each moment, accounts to himself for what he has heard" (4). Such a listener is fully conscious, fully attentive, and able to hear longitudinal, structural relationships in large-scale musical works. Adorno goes on to say, "Spontaneously following the course of music, even complicated music, he hears the sequence, hears past, present, and future moments together so that they crystallize into a meaningful context" (4). The listening he describes is recognizable to all of us who have come through music education-it is in various ways the model of what we know about common practice or tonal music.

Adorno's model of listening is, for instance, a reasonable description of one way to listen to works in sonata allegro form. What's important for my purposes is its obvious structural analogy to more representational narrative forms. What it means to "hear the sequence" is the capacity to follow a theme throughout its journey, as narratologists would put it, away from and back to home. The listener who "hears past, present, and future together" is following the plot, relating current musical events to past and future ones, "so that they crystallize into a meaningful context" (Adorno 1988: 4). The identity of the expert listener, for Adorno, is predicated on his ability to recognize and follow the musical narrative.

In McClary's case, too, the presumption of narrative as an organizing principle is not solely of her own making. The developments of feminist theory in literary and film studies on which she draws relied heavily on psychoanalysis and on structuralist narratology. Of course, in McClary's case, she's entirely aware of her concern with narrative; in a footnote in the introduction to Feminine Endings (1991), she says: "The essays in this volume are concerned with problematizing the historicity of narrative processes in music" (171n2I). In the text itself, she is never quite this blunt, but nearly. She goes on, shortly after that footnote, in the main text: "The sonata procedure that comes to characterize instrumental music of the eighteenth and nineteenth centuries features a more polarized version of that basic narrative paradigm. In sonata, the principal key theme clearly occupies the narrative position of masculine protagonist" (15). 
McClary outlines five component strategies to her approach-musical constructions of gender and sexuality, gendered aspects of traditional music theory, gender and sexuality in musical narrative, music as a gendered discourse, and discursive strategies of women musicians. Of these, it is the third, gender and sexuality in musical narrative, that has occasioned the worst vitriol. Particularly controversial was her analysis of Tchaikovsky's Fourth Symphony, in which she argued that certain unconventional harmonic strategies might be read in relation to Tchaikovsky's sexuality. "For what we have is a narrative in which the protagonist seems victimized both by patriarchal expectations and by sensual feminine entrapment: both forces actively block the possibility of his self-development. . . To deny [Tchaikovsky] the option of having devised unconventional stories-stories that were informed by his own experience (though always, of course, heavily mediated through the technical specificity of formal, harmonic, and orchestrational procedures)—is to continue to silence him by pushing him into some kind of assumed uniform patriarchal grid: precisely that against which he fought his whole life" (McClary 1991: 76-78). Think what you will about the relationship between the symphony and Tchaikovsky's sexual identity, but McClary's reliance on narrative and narration for the structure of her argument is as clear as was Adorno's.

The case I'm trying to make here is this: from the abstract, formal relationships heard by Adorno and his fellow expert listeners to the articulation of desire to harmonic procedure in McClary's theorization, our models of how to think about music rely on linear narrativity. And as much as thinking narratively about music has taught us-and I certainly think it has taught us a great deal-perhaps a different paradigm will offer us some new insights. ${ }^{8}$

In place of narrativity, I am proposing that we consider how we listen to ubiquitous musics, and how that listening engages us in sensual and sensory affective processes to situate us in fields of distributed subjectivities. But what does that mean in practice? Listening is a peculiar activity, after all. Like seeing, listening engages both representational (e.g., spoken language) sounds and sounds understood to be nonrepresentational (e.g., much of Western music, both classical and popular). But unlike visual culture, scholarly discourse is quite underdeveloped in many areas of listening and sound studies, and general public discourse is not any better. Because of this, theorizations of listening and formations of subjectivities have been relatively few; nevertheless, distributed subjectivity, as I am theorizing it, is very much an aural process. 
I want, here, to argue that the production of affective responses to ubiquitous musics, through a range of partially attentive listenings, is how distributed subjectivities come into being. This is the last central term of this book, and it, too, will require some definition.

\section{DISTRIBUTED SUBJECTIVITIES}

Distributed subjectivity is my own version of a phenomenon many people have set out to describe in varying ways. Cyborgs (e.g., Haraway 2003), the network (e.g., Castells 1996-98), and rhizomes (Deleuze and Guattari 1987) are among the best-known versions. I am choosing a different term because I want to specify several things:

- Individual subjectivity continues to appear to us to function, even as many of the notions on which it was based have deteriorated or disappeared (the bourgeois family, Enlightenment individuality, and so on), so a plausible theory has to take account of its force in absentia, as it were, or what I earlier called the individual-subjectivity-function.

- Distributed subjectivity is constructed in and through our responses to acts of culture- speech, music, television, and the like-in ways very similar to how we once theorized individual subjects were formed, but through different processes.

- Music has a very privileged place in this formation; it is ubiquitous musics that bond and bind the field of distribution together. They are, in a sense, the channels of distribution. They put in place the experience of the network avant la lettre, as it were, creating the experience of distribution from the materials of broadcasting, that is, from the cables of Muzak and the airwaves of radio. In this sense, it is possible to suggest, along with Jacques Attali (1985), that in the circulation and engagement with music in its mass cultural forms, the shape of another social order in the making, the form that would supplant mass media culture, could be and indeed was heard.

- While the Enlightenment bourgeois subject has disappeared, the feeling, the apprehension of individual subjectivity, should not be belittled in our models (see Venn 1997). We are nodes in a massive, widespread field of distribution, it is true, but 
nonetheless nodes with, potentially, an agglomeration of experiences and accretions of affect that are uncommon, or perhaps even unique.

Distributed subjectivity is, then, a nonindividual subjectivity, a field, but a field over which power is distributed unevenly and unpredictably, over which differences are not only possible but required, and across which information flows, leading to affective responses. The channels of distribution are held open by ubiquitous musics. Humans, institutions, machines, and molecules are all nodes in the network, nodes of different densities.

\section{DISTRIBUTING SUBJECTIVITY}

I have taken the language of "distribution" from another computer phenomenon, distributed computing, because it is an apt visualization of what I am trying to describe. But first, it is crucial to point out that distributed computing necessarily comes after the development of distributed subjectivity, and therefore makes a strange metaphor. Distributed computing is only possible because it was imaginable, and it was imaginable precisely because both the forms of thought and the physical forms were already in place to enable it, as I hope to clarify.

Desktop computing treats the computer as a discrete entity; like the Enlightenment subject, it relies solely on the processing power contained within itself. Distributed computing, however, links smaller units together so that they can share processing power in a pool of sorts. For example, The Chronicle of Higher Education (the U.S. academic weekly newspaper of record) reported on 29 November 292002 that "a team of university researchers has verified that a large-scale computer model employing distributed-computing technology can accurately simulate protein folding, a crucial biological process. The model was run on about 40,000 machines worldwide, taking an amount of work usually reserved for supercomputers and breaking it into chunks small enough for personal computers to handle over the Internet." In this way, the unused processing power of many small computers is aggregated to make enough power to address very large-scale questions.

Now, even what we might term something like "brain power" is distributed, as is clear in another protein-folding research project:

Aristides is a typical 13-year-old boy. He plays basketball after school, is learning the clarinet, and in the evening sits in front of his computer playing games. There is one game that he is especially keen 
on, however, which marks him out from his peers. Every day he logs on to www.fold.it, where, under the nickname "Cheese," he plays a game that involves twisting, pulling and wiggling a $3 \mathrm{D}$ structure that looks a bit like a tree's root system. He manipulates different lengths of these snaking green tubes until they fit into the smallest volume possible. It may sound like a rather bizarre game-a distant ${ }_{3} \mathrm{D}$ relative of Tetris, perhaps-but it is in fact a brilliant disguise for one of the toughest conundrums facing biologists today: how do proteins fold? (Dartnell 2008)

By accumulating processing power-be it human or machinic-into a collective process, researchers are approaching problems that were until very recently well beyond the scope of human research. In fact, many research tasks are advertised as piece work on Amazon's Mechanical Turk page, where workers (who are a complicated group demographically; see Ipeirotis 2010) perform what are called "Human Intelligence Tasks," or HITs, for a few cents per item. For example, on 29 April 2012, there were 159,060 HITs available, including tasks such as finding email addresses of restaurant managers, providing Google Search ranking of particular URLs, or choosing the best category for a particular link. This enables people with some programming skills to access a collectivized pool of human intelligence to solve problems. (There have also been some intriguing art projects using Mechanical Turk; see, e.g., Koblin 2011.)

But once connectivity of these various kinds comes into being, it brings to the surface a new form of subjectivity that was already in process and that enabled the pieces to develop. Each computer and each person, then, is a dense node in a network, neither discrete nor flattened. Such a perspective on processing power offers a powerful description of contemporary subjectivity; each person - as well as many nonhuman components-is a dense node in an enormous field that is addressed by various participants in various ways and with varying degrees of power, composing, I am arguing here, a mobile terrain of ebb and flow, of power and information. Distributed subjectivity suggests a vast field, rather than a group of subjects or an individual subject, on which various connections agglomerate temporarily and then dissolve again. This field is significantly constructed through and with music.

\section{AFFECT AND IDENTITY}

The notion of distributed subjectivity could raise some concerns that have been leveled at Deleuze and at many works in his wake. How do identity 
and identification work in this new form? And since so much of what we know about power and the political is based on identity in some form or another, how do we imagine the political as a realm when identity is seen differently?

Perhaps it's best to begin with an attempt to understand something like identity in relation to distributed subjectivity and affect. As quoted earlier, Massumi says about this question that position no longer seems obvious or central, and that process no longer seems beyond reach; rather, process leaves behind a residue of position, which is thus secondary. In other words, identity is the trace of affect. There has been an insistence that affect cannot deal with identity, because affect happens in constant flows and identity is static. Rather, the point is simply this-identity is one of the formations that are left behind after affect does its work. But, as I hope will become clear, identity only appears to be a static formation. From moment to moment, in different contexts, the boundaries of any given identity will shift and change, sometimes quite radically, which suggests that the idea that identity is positional and static is a description of something that is believed and not a description of how identity actually happens.

Some concrete examples might help here. When I am away from Armenians for a long time, my sense of my own Armenianness-my identity as an Armenian, or perhaps the place of "Armenian" in my identitybecomes attenuated. When I am in a particularly conservative crowd of Armenians-if strong nationalist, patriarchal, and heteronormative discourses are bouncing around the room-I feel even less Armenian. I feel "written out." This is the point of distributed subjectivity. Identity doesn't reside within a single subject; rather, it is a flow across a field, which constantly morphs into different shapes and contours, depending on the circumstances. Distributed subjectivity acknowledges that at some places at some points in time, I will-or will not-be included in any given identity category. While such identities seem static and positional, they are anything but, and they are constituted microsecond by microsecond according to affects that are in motion through and across a field that might be constituted of body parts, or verbal texts, or sounds, or machines, or groups, and most likely all of the above.

There is a statistical question here-what will become actual depends on the frequency of a particular kind of event on the plane of immanence on the one hand, and the frequency and size of actual events on the other. In The Deleuze Dictionary, Cliff Stagoll (2005) says: "A plane of immanence can be conceived as a surface upon which all events occur, where events are understood as chance, productive interactions between forces of 
all kinds. As such, it represents the field of becoming, a 'space' containing all of the possibilities inherent in forces" (204). But "becoming" does not preclude events. If an event is common, as in the case of certain kinds of events for most identities, things will attach to it, it will get bigger, which means things will attach to it more easily. The singing of a national anthem might be a good example here. For many people-though certainly not all-their national anthem invokes pride and community, a warm feeling of belonging. Each singing is an affective event, creating a wave of feeling that flows across a group of any size, from one to thousands. Affect like that leaves behind residue that appears to produce a static identity. But the very fact that it needs to be done over and over suggests that something rather different is happening.

There is another crucial difference between the version of identity that $I^{\prime} \mathrm{m}$ proposing here and the more standard ones. The latter are usually set within an individual, whereas nothing about the plane of immanence is containable, and nothing about distributed subjectivity operates through containment. This is perhaps the single most important difference to be contemplated, as well as the most challenging.

If we want to track the production of identity through affect in music in a particular case, it would be impossible; there are too many tiny little events, spread out over vast terrains. But a grossly oversimplified outline of a process would sound something like this:

- A series of sounds my mother is singing happen for and around baby me-a lullaby handed down through generations in my family. It has certain musical features, and it happens in the context of some of the few actualities a baby has: comfort, soft warmth (in this case, mother), and perhaps other arms and mouths (for me, great-aunt and grandmothers). On the plane of immanence, among all the many events taking place, there are bodily events being shared, quite literally, by my mother and baby me. The sounds themselves are also events on the plane of immanence.

- Those sounds attach to those bodily events, and there begins to be a relationship between the musical features of that song and a certain shared state.

- Across the years, I continue to hear similar musical features in music I hear in Armenian settings. Because in our household (as in many Armenian diasporan households), Armenian has a 
very big place among categories of events, they frequently get labeled that way. (They could be labeled Turkish or Near or Middle Eastern, for instance, but never are.) More importantly, we hear them together, in conjunction with shared bodily events (increasing or decreasing heart rate, for example).

- On the one hand, such sequences of musical features have physiological correlates, because they are part of a response complex through previously accreted experiences, perhaps beginning with the lullaby. On the other hand, I recognize consciously that those responses come to me with similar music, and I think that those sounds are Armenian. And each experience deposits a bit more affect.

- Ultimately, over time and through repetition, I come to have a strong and recognizable affective response to Armenian music. This, along with similar processes related to food, art, language, stories, and the like, helps to produce what I think of as my Armenian identity.

Of course, the process I've outlined is simplified-to archive the process well would require a level of detail that cannot be of interest to anyone, not even me. And from another perspective it is completely impossible, since the plane of immanence is always virtual, in Deleuze's terms, not actual, but possible, not present, but "belonging to the pure past-the past that can never be fully present" (Boundas 2005: 297). Moreover, the Armenian part of my identity is the easiest to describe in this way, since it is musically distinct in certain ways; nonetheless, my gender, sexual, class, physical ability, and other identities are all formulated through similar processes. If we remember that affect is the physiological process that leaves behind deposits that we later recognize as emotion, then it is easy enough to see identity in Massumi's (2002) terms, as "retro movement, movement residue" (7).

From this perspective, identity does not need to disappear, nor does it need to be the first axis of thought. Identity is a position left behind by the work of affect, and while it has been perceived as positional- that is, as static-it now looks like a constant process. ${ }^{9}$ Affect happens over microsecond intervals, moving on and leaving traces behind before we can even feel its presence. Affect both conditions and enacts identities and identifications, and it does so not within bodies, but across them. 


\section{THE CHAPTERS}

The chapters that follow work at understanding the relationships of the six terms-ubiquitous musics, listening, affect, the senses, attention, and distributed subjectivity-in different settings. Chapter $I$ is focused on the question of defining ubiquitous music, and thinking about how to understand distributed subjectivity. In it, I consider music at home, and especially imaginations of the place of music in homes of the near future, to think about what they tell us about listening.

Chapter 2 is about three works by Armenian women video artists from around the world, and it discusses ideas about affect and engagements with sounds. Chapter 3 considers the place of the senses in a type of film I think of as a new genre-the simplistic story with lots of sophisticated computergenerated images and great surround sound (and) music. These are films that clearly move away from organization around plot and character and depth toward a continuous roller-coaster ride of hyper sound and vision.

Chapter 4 discusses how music and television, those media that taught us a particular kind of attenuated, fragmented, unfocused attention, joined forces in a certain period to try to recapture our attention through creation of musical episodes for TV series. Chapter 5 describes three bands who draw on traditional Armenian musical materials and jazz to fuse them into something new, and how particular experiences of listening to their music helped me rethink how I live out my Armenian identity. Chapter 6 addresses the main form of ubiquitous musics, that is, what most people would casually refer to as "background music." It is about music in retail space, and the specific cases of Starbucks and Putumayo.

In the conclusion, I offer a recapitulation of my argument and the ways the central terms orbit each other. But I am more concerned there to open new questions and new problematics that arise from this perspective on listening, affect, and distributed subjectivity. What I am calling for is nothing less than a wholesale rethinking of the way we think about, talk about, and study music, and ourselves in it. 